rev.relac.int.estrateg.segur.5(2):39-71,2010

\title{
TIMOR-LESTE O LA CONSTRUCCIÓN DE LA NACIÓN EN UN ESTADO FALLIDO*
}

\author{
Walter Cadena Afanador* \\ Camilo Devia Garzón ${ }^{* * *}$
}

\section{RESUMEN}

Timor-Leste es el Estado más joven y más pobre de Asia. Su surgimiento como Estado se ha constituido en un interesante laboratorio para la reinterpretación de las teorías clásicas sobre la construcción de la nación, del Estado, su reconocimiento internacional y la viabilidad institucional. Este documento hace un recorrido sintético por los principales hechos históricos que han contribuido en la formación de la República Democrática de Timor-Leste, así como los factores que han incidido en su reconocimiento como Estado.

* Este trabajo es producto del proyecto EES-583 «Deconstrucción del Estado nación contemporáneo», adscrito al grupo «Estudios Internacionales y Políticos» de la Facultad de Relaciones Internacionales, Estrategia y Seguridad de la Universidad Militar Nueva Granada (UMNG).

** Abogado, Magíster en Relaciones Internacionales. Director del Centro de Investigaciones FARIES UMNG, Docente investigador de la Universidad Libre. walter.cadena@unimilitar.edu.co

*** Profesional en Relaciones Internacionales y Estudios Políticos, Joven investigador. camilodevia@gmail.com. Se destaca la colaboración en este proyecto de siete estudiantes investigadores. 
La construcción de la nación, desde una perspectiva de comunidad imaginada, entra en conflicto con la catalogación de Timor-Leste como un Estado fallido. Al respecto, se abordan los conceptos de Estado colapsado o fallido y su aplicabilidad en el caso de Timor. De igual manera, se esbozan algunos retos planteados a partir de su independencia, como son el proceso de reconciliación y reconstrucción de memoria histórica, de identidad y lingüísticos, así como aspectos socioeconómicos y geopolíticos.

Palabras clave: Timor-Leste, Descolonización, Libre determinación, Construcción de nación, Estado fallido.

\section{ABSTRACT}

Timor-Leste is the youngest and poorest state in all Asia. Its birth as a State has become an interesting laboratory for the reinterpretation of classic theories about state-building, nationbuilding, international recognition and institutional sustainability. This document makes a summary review of the most important historical facts that have contributed to the creation of the Democratic Republic of Timor-Leste, as well as the factors that have affected its acknowledgment as State.

The construction of the nation, from the perspective of an imagined community, conflicts with Timor-Leste being catalogued as a failed state. In this respect, the concepts of failed or collapsed state and their applicability in the case of Timor, will be addressed. Likewise, this work will outline some challenges brought by its independence, such as the process of reconciliation and rebuilding of the historic memory, identity and language, as well as socioeconomic and geopolitical issues.

Key Words: Timor-Leste, Decolonization, Self-determination, Nation-building, Failed state.

\section{INTRODUCCIÓN}

Timor-Leste es el primer Estado del segundo milenio en ser reconocido por la comunidad internacional, al ingresar como miembro a las Naciones Unidas el 27 de septiembre de 2002. Su reconocimiento como Estado fue producto de un prolongado proceso que duró cerca de tres décadas desde el momento en que Portugal abandonó el país en 1975.

La primera lectura que se hace al proceso de independencia de Timor Oriental ${ }^{1}$, desde el campo de las relaciones internacionales, tiene que ver con las teorías de la descolonización, que

1 Se utilizará la acepción de Timor Oriental al territorio del actual Estado de Timor-Leste, cuando este aún no había alcanzado la independencia.

TIMOR-LESTE O LA CONSTRUCCIÓN DE LA NACIÓN EN UN ESTADO FALLIDO 
surgieron como un fenómeno estructural dentro de un reacomodamiento de los poderes hegemónicos regionales y mundiales, tras la Segunda Guerra Mundial. En buena medida, una de las causas para que desde Europa estallaran las dos conflagraciones bélicas a comienzos del Siglo XX fue la creciente carrera colonizadora que habían iniciado las potencias europeas a partir de la segunda mitad del Siglo XIX.

El esquema colonial desarrollado, fundamentalmente por Alemania, Inglaterra, Francia, Países Bajos, Italia, Bélgica y Portugal, desencadenó la insostenibilidad del modelo europeo basado en el balance de poder, pues aceleró las rivalidades históricas, alimentadas por componentes culturales, socioeconómicos y de la consolidación de sus propios proyectos de Estados nación.

De allí que una vez finalizada la Segunda Guerra Mundial no fue de extrañar una reconfiguración de los denominados países descolonizados, en torno a lo que se denominó como Tercer Mundo. Estos países hicieron lo posible por formar un bloque alternativo de estados con el fin de que jugaran un rol autónomo frente al dominio hegemónico de la comunidad internacional por parte de las dos superpotencias, esto es, los Estados Unidos y la Unión Soviética (Hobsbawm, 2008, pp. 346 y 358).

Este proceso impulsó la discusión dentro del seno de las Naciones Unidas en torno al derecho a la libre determinación de los pueblos, debate que permitió, a finales de las década de 1950 y comienzos de la década de 1960, dinamizar un proceso de descolonización que logró su mayor nivel en la década de 1970. Fue precisamente durante esta década que se vislumbró la posibilidad de materializar el deseo de libre determinación del pueblo timorense en aquella apartada colonia portuguesa de ultramar. Sin embargo, Timor Oriental vivió uno de los más prolongados y violentos procesos de descolonización de los que se desarrollaron durante el Siglo XX.

Uno de los aspectos que más llama la atención en la prefiguración del Estado de Timor Oriental es la necesidad sentida de construcción de narrativas históricas que configuren una memoria colectiva en torno a la identidad nacional. Siglos de negación de lo autóctono, primero por parte de la colonización portuguesa, y después por parte del dominio gubernamental indonesio, dejaron serios vacíos dentro del discurso historiográfico del pueblo timorense, lo cual ha afectado de manera estructural su consolidación como Estado nación.

A partir del proceso de descolonización surgido desde la década de 1970 se ha iniciado un proceso de construcción de la historia de este pueblo, proceso que se aceleró a partir del periodo de independencia del país. En tal sentido, es importante el esfuerzo realizado desde muchos ángulos para redescubrir los orígenes de la nación timorense, a partir de su propia historia.

Para efecto de este trabajo, se considera que es fundamental el aporte dado dentro de este proceso por el Informe Comisión para la Acogida, la Verdad y la Reconciliación (CAVR) denominado Chega! (Basta, No más), publicado en octubre de 2005 (en adelante se llamará Informe 
Chega), ya que dicho informe es un notable «esfuerzo por proveer una narrativa de la historia nacional de Timor Oriental» (Webster, 2007: p. 581).

Se identifican tres periodos históricos en la construcción del Estado de Timor Oriental: Primero, la colonización portuguesa y la presencia holandesa en la isla. Segundo, la anexión indonesia, caracterizado por un progresivo rechazo recíproco de los timorenses hacia la invasión y de Indonesia por asimilar socialmente a los timorenses. Tercero, la independencia de la República Democrática de Timor-Leste y su estructuración como nación (Ver Gráfica No. 1).

\section{Gráfica No. 1. Periodos históricos en la construcción del Estado de Timor Oriental}

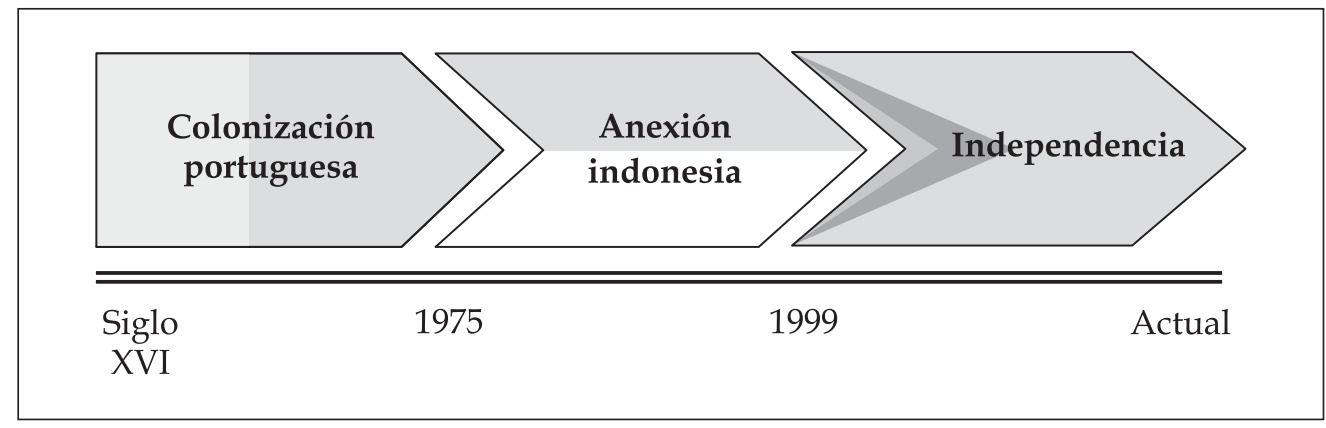

Elaboración propia.

\section{EL LEGADO COLONIAL}

\subsection{La colonización portuguesa: entre el dominio y el olvido}

Tal como se identifica en el Informe Chega, uno de sus objetivos consistió en convertirse en un paso crucial en la construcción de nación, pues recogió muchas apreciaciones y vivencias de la gente timorense del común, así como de líderes políticos y gubernamentales, tanto de TimorLeste como de otros Estados, como son los de Indonesia, Australia, Portugal y Estados Unidos, las Naciones Unidas y organizaciones gubernamentales y no gubernamentales:

Si bien la historia es fundamental para construir una nación, una historia simplista que pretenda barrer bajo la alfombra realidades desagradables o hacer invisible la contribución de personas de todos los sectores de la vida no puede ayudar a construir una nación resistente y sostenible. La historia dice que reconociendo la complejidad, se construye espacio para la voz de los que a menudo son silenciados, y abre el camino para la reflexión abierta que pueda contribuir para construir una nación basada en la idea de la fuerza del respeto 
por los demás, el pluralismo y la democracia sustentada en la igualdad de todos los ciudadanos. (CAVR, 2005, Parte 3, 2, traducción libre).

La búsqueda de sándalo fue el principal motivo por el que los portugueses arribaron a Timor a comienzos del Siglo XVI. Luego de conquistar Malasia, en 1511, los portugueses desembarcaron en la isla de Timor, en la región de Oecusse, donde construyeron la primera iglesia en Lifau, en 1590 (CAVR, 2005, Parte 3, 12). La región de Oecusse actualmente hace parte de la República Democrática de Timor-Leste, a pesar de estar rodeada por territorio indonesio y es considerada como la cuna histórica de la nación timorense.

En torno a Lifau, al norte y el oriente de la isla, se establecieron pequeñas comunidades descendientes de marinos, comerciantes y colonizadores portugueses. Esta mezcla mestiza fue denominada como topasses, quienes jugaron un papel importante en los levantamientos emancipadores de la población timorense, en la búsqueda de reivindicaciones sociales y autonomía administrativa (CAVR, 2005, Parte 3, 12-13). Los topasses no sólo fueron un grupo mestizo en Timor, sino que formaron una mezcla racial entre los portugueses y los nativos del Sudeste asiático.

La Compañía de las Indias Orientales Unidas, conocida por sus siglas VOC en holandés, fue la punta de lanza del proceso colonizador emprendido por los Países Bajos. Sobresalen dos características de la colonización holandesa: 1) se desarrolló a través de empresas mercantiles de capital mixto, esto es, con recursos privados y públicos; 2) la mayoría de los territorios colonizados eran insulares o de pequeña extensión, tal como sucedió en el Caribe, África y el Sudeste Asiático. En esta región, la isla de Timor también fue punto de referencia para los Países Bajos, que colonizaron la zona occidental, en particular, alrededor del enclave de Kupang.

Durante el Siglo XVIII se presentaron varios enfrentamientos bélicos entre las dos potencias colonizadoras de la isla de Timor, que desembocaron en la batalla de Penfui, en 1749; este hecho permitió establecer de facto las fronteras coloniales en la isla (Taylor, 2001, p. 205). Las fronteras sobre el archipiélago de Timor y Solor fueron ratificadas a través del Tratado del 20 de abril de 1859, firmado en Lisboa por las dos potencias colonizadoras. Dicho Tratado fue complementado con la Convención del 10 de junio de 1893, también firmada en Lisboa por ambas partes, la cual demarcó con exactitud la frontera (Krieger y Rauschning, 1994, pp. 1-3).

Sólo hasta un siglo después de su arribo a Timor, los portugueses oficializaron en 1702 su presencia en el asentamiento de Lifau, el cual sería administrado desde la lejana colonia de Goa, ubicada en el subcontinente hindú. Por supuesto, la distancia que las separaba hizo artificial dicho control ${ }^{2}$. Sólo hasta dos siglos después, en 1896, Portugal determinó separar Timor del

2 Por vía marítima, un viaje desde Goa hasta Dili supera las 4.000 millas náuticas de distancia, esto es, una distancia similar a la que hay entre Colón (Panamá) y Lisboa. 
distrito de Goa. Ello denotó la escasa importancia que tuvo históricamente la isla para Portugal, la cual sólo cobró cierta relevancia finales del Siglo XIX (CAVR, 2005, Parte 3, 13 y 21).

La estrategia del gobierno portugués en la dominación colonial en la isla se orientó en dos sentidos: Por un lado, existió una escasa política en generar desarrollos en materia de infraestructura o institucional, pues el único interés que existía por la isla se dio en términos de explotación, expoliación o extracción de materias primas a escalas limitadas. Y, por otro lado, Portugal aplicó la premisa de quien divide, reinará: la metrópoli estimuló de manera constante las rivalidades ancestrales entre los reyes de las tribus timorenses, conocidos como liurai:

Para los portugueses, el precio de esta política de divide y vencerás fue la localización de una persistente resistencia hacia la autoridad portuguesa. Para los habitantes de Timor Oriental, el precio fue su perpetua debilidad y desunión. (CAVR, 2005, Parte 3, 2, traducción libre).

A pesar de estas divisiones internas, a finales del Siglo XVII y durante la primera mitad del Siglo XVIII se presentaron diversos levantamientos liurai, que volvieron insostenible el dominio portugués en el enclave de Lifau. De allí que para 1769 se trasladó la incipiente estructura colonial a Dili, que más tarde se convirtió en el heartland del desarrollo colonial y postcolonial de la mitad oriental de la isla.

Timor Oriental siempre representó para Portugal una posesión colonial marginal, debido a que no poseía recursos mineros ni materias primas valiosas que fueran de fácil extracción. Así mismo, no se dio una permanente explotación intensiva de la mano de obra durante la dominación portuguesa. Se desarrolló la política de sembrar cultivos de especies no nativas, como el café, lo cual movilizó a trabajos forzados de un número considerable de timorenses hacia estas nuevas plantaciones (CAVR, 2005, Parte 3, 21).

A partir de la década de 1890 se aplicaron de manera sistemática políticas coloniales de incremento en los impuestos, así como de trabajos coercitivos, que fueron profundamente impopulares, lo que estimuló el surgimiento de la más fuerte de las rebeliones de los liurai hasta ese momento, liderada por Dom Boaventura, un rey liurai. Durante dicha revuelta, los liurai rebeldes organizaron un ejército dotado de armas primitivas, mientras Portugal conformó un ejército de 12.000 hombres provenientes de liurai aliados y además trajo tropas desde Mozambique para repeler la rebelión. Se estima que murieron alrededor de 25.000 personas durante la campaña militar (CAVR, 2005, Parte 3, 21).

Dom Boaventura es considerado por los timorenses como un gran líder nacionalista, ya que mantuvo su lucha de resistencia durante 16 años, desde 1895 a 1912 (Taylor, 2001, p. 210). De allí que Timor fue la última colonia portuguesa en ser completamente pacificada (Krieger y Rauschning, 1994, p. 97). 


\subsection{Cambios en la Metrópoli y la ola de la descolonización}

De manera paralela, durante la transición del Siglo XIX al Siglo XX, Portugal atravesaba una época de inestabilidad nacional. En febrero de 1908 el rey Carlos I y su hijo heredero fueron asesinados en las calles lisboetas ${ }^{3}$. El sucesor en el reinado fue el segundo hijo de Carlos I, quien se llamó Manuel II. Su reinado fue efímero, pues fue depuesto en $1910^{4}$, terminando así con 275 años de dominio de la casa de Braganza y 771 años de monarquía en Portugal. En 1915 y 1917 hubo dos breves dictaduras militares germanófilas. El caos financiero sólo comenzó a disiparse con la designación, en 1928, de António de Oliveira Salazar como Ministro de Finanzas. Salazar fue durante las siguientes cuatro décadas la figura política dominante de Portugal (Asimov, 1992, pp. 627, 660, 736 y 767).

Durante la Primera y la Segunda Guerra Mundial, de manera paradójica, la población de Timor Oriental sufrió mucho más los embates de la conflagración bélica que surgió en Europa, que la propia metrópoli colonizadora. Portugal se afectó muy poco durante la Primera Guerra Mundial, a pesar de haberle declarado la guerra a Alemania y, en la Segunda Guerra Mundial, tanto Portugal como Suiza se declararon neutrales. Sin embargo, la neutralidad no las eximió para que sus colonias fueran escenarios bélicos por parte de los países del Eje.

Estos hechos sucedieron en Timor Oriental, donde las tropas australianas, holandesas y británicas se asentaron a partir de diciembre de 1941 en su territorio para contener la posterior invasión japonesa, en febrero de 1942. Se considera que hubo entre 40.000 y 60.000 timorenses muertos, esto es, el 14\% de la población que existía (Taylor, 2001, p. 211), donde muchos de ellos fueron torturados y asesinados por el ejército japonés. También se presentó un alto número de casos de esclavitud sexual (CAVR, 2005, Parte 3, 23-24).

La política portuguesa hacia Timor después de las dos guerras mundiales no cambió mucho. De por sí, durante el gobierno dictatorial de un solo partido, encabezado por el mandato de Salazar, se fortaleció la anticuada posición de preservar sus colonias a ultranza, alimentando el nacionalismo en la metrópoli. Esta posición fue criticada por la comunidad internacional, debido a que, entre otros documentos, la Carta de las Naciones de 1945, en su Artículo 73, demandó de las

3 Este regicidio fue consecuencia de la creciente insatisfacción popular frente a la desgastada estructura monárquica portuguesa, la cual se expresó en los levantamientos de 1890 en reacción a la crisis colonial en África y el ultimátum británico. Este descontento acumulado se galvanizó a partir de los excesos dictatoriales del primer ministro, João Franco.

4 Manuel II asumió el trono cuando tenía 18 años de edad. Trató de liberalizar el gobierno, pero sus extravagancias personales exacerbaron el deseo de cambio de modelo de gobierno en los republicanos quienes, alentados por su triunfo en las elecciones de julio de 1910, apoyaron el levantamiento popular que sucedió tres meses después y que desembocó en el derrocamiento de la monarquía y la proclamación de la República. 
potencias colonizadoras que dejaran dichos territorios de manera gradual, introduciendo mayores niveles de autonomía. Esa declaración, relativa a los territorios autónomos, vinculó de manera explícita a Timor Oriental cuando fue enlistada por las Naciones Unidas en 1960 como un territorio no autónomo bajo la administración de Portugal ${ }^{5}$.

Dentro de la ola de descolonización que sacudió al mundo, a partir de la década de 1960, Portugal rechazó la tendencia mayoritaria, arguyendo que era un país pluricontinental, y trató de retener sus colonias ${ }^{6}$ mediante el uso de la fuerza. Sin embargo, este esfuerzo le costó muchas vidas y dinero que afectaron a la que era considerada como la economía más pobre de Europa occidental, con una renta per cápita de mil dólares para finales de la década de 1950. La presión de la que fue objeto Portugal por parte las principales potencias, a través de las Naciones Unidas, la llevaron a su aislamiento internacional (De la Torre y Sánchez, 1992).

La importancia de Timor Oriental para Portugal no fue relevante, pues era concebida como una región profundamente montañosa y selvática, lejana de la metrópoli y sin mayores recursos para la explotación, excepto el sándalo, miel, cera y el tráfico de esclavos. De igual forma, el interior de la colonia era poco accesible y estaba habitado por tribus que hablaban una docena de dialectos indescifrables.

El impacto portugués en la Isla se concentró básicamente en tres factores:

a) Jugaron con la población nativa, generando conflictos entre las diversos grupos sociales para que tuviesen alianzas débiles, afectando la construcción de la nación.

b) No se desarrollaron tradiciones de autogobierno, dándose un sistema de gobierno feudal (en contraposición al poder histórico de los liurai).

c) No se institucionalizaron o desarrollaron valores democráticos ni sobre derechos humanos, aunque sobrevivieron ciertos valores tradicionales y otros que fueron incorporados a través de la Iglesia Católica (CAVR, 2005: Parte 3, 11).

Se puede afirmar que el papel que jugó Portugal durante la época de la colonización fue irrebatible en cuanto al dominio territorial en la zona oriental de la isla; no obstante, al poder colonizador no le interesó durante mucho tiempo construir estructuras e instituciones, que fueran

5 Resolución 1542 (XV) de la Asamblea General de Naciones Unidas del 15 de diciembre de 1960. Dicha Resolución fue aprobada por 68 votos a favor y 6 votos en contra, 17 abstenciones y 8 países ausentes. (Krieger y Rauschning, 1994, pp. 29-30).

6 Entre las principales colonias portuguesas se encontraban Angola, Cabo Verde, Goa (Damán y Diu), Guinea, Mozambique, Sao Tomé y Príncipe, Macao y Timor Oriental.

7 Esta postura obtusa frente a la no descolonización llevó al país «(...) a un anquilosamiento de las estructuras industriales, a la falta de inversión, a una agricultura primitiva y a la alta fiscalización a que obligaban los gastos de las guerras coloniales» (Carcedo, 2007, p. 77). 
transplantadas desde la metrópoli y que permitieran la consolidación, siquiera de manera incipiente, de los cimientos futuros de una nación o de un Estado postcolonial. Estos elementos serán determinantes en la gestación de Timor-Leste como comunidad imaginada (Anderson, 1983).

\subsection{La descolonización truncada por la anexión}

En 1968 Salazar fue reemplazado, luego de cuatro décadas de dominio, por Marcelo Caetano. El nuevo presidente no logró responder a las apremiantes necesidades de su país, hecho que desencadenó en un golpe militar, en abril de 1974, con el apoyo masivo y espontáneo de la sociedad civil. Este acontecimiento fue denominado como la Revolución de los Claveles, el cual derrocó al régimen que gobernaba desde 1926 con el nombre de Estado Novo.

Una vez instalado el gobierno provisional en Portugal en cabeza del general Spínola, quien fue el líder del movimiento golpista, se emitió el Decreto No. 203/1974 por el cual se estableció una política de descolonización basada en el principio de la autodeterminación. En tal sentido, el Ministro de Relaciones Exteriores y también líder del Partido Socialista, Mário Soares, no compartía la postura federalista del jefe de gobierno y, más bien, fue partidario de la independencia de las colonias. Finalmente, esta posición fue asumida por el gobierno a través de la Ley 7/1974 (CAVR, 2005, Parte 3, 35-38).

Los acontecimientos en la lejana metrópoli fueron seguidos con euforia y preocupación en Timor Oriental, pues la población era consciente de que no estaba preparada para estos cambios (CAVR, 2005, Parte 3, 40).

Sin embargo, en 1974 surgieron algunas organizaciones políticas como la Unión Democrática Timorense (UDT en portugués) ${ }^{8}$, la Asociación de Demócratas Timorenses (ASDT en portugués $)^{9}$, que cuatro meses después se denominó Frente Revolucionario para la Independencia de Timor-Leste (Fretilin en portugués), y la Asociación para la Integración de Timor con Indonesia (Apodeti $^{10}$. También surgieron otros partidos políticos pequeños como la Asociación de los Hijos Timorenses Guerreros (KOTA en tétum), El Partido Laborista y la Asociación Democrática para la Integración con Australia (Aditla). Los dos partidos que inicialmente acapararon el mayor apoyo popular fueron la UDT y la ASDT (CAVR, 2005, Parte 3, 44-50).

8 Fundada el 11 de mayo de 1974, su orientación inicial fue conservadora. Eran partidarios de un periodo de federación con Portugal para una eventual independencia posterior. Rechazaron la integración con otros países.

9 Fundada nueve días después de la UDT, estaba integrada en sus inicios por jóvenes intelectuales timorenses, quienes abogaron por la independencia manteniendo una posición nacionalista y anticolonial.

10 Fundada el 27 de mayo de 1974, contó desde sus inicios con el apoyo político y financiero del gobierno de Indonesia, a través del cónsul en Dili. Buscó desde un principio la integración autónoma con Indonesia. 
La descolonización portuguesa del territorio fue truncada por la anexión indonesia. El contexto geopolítico en el Sudeste asiático para 1975 era crucial, por cuanto había sucedido la victoria del Vietcong tras la caída del gobierno de Saigón, así como los triunfos comunistas en Camboya y Laos. Indonesia, encabezada por su presidente Suharto, contaba con el apoyo estadounidense debido a su lucha contra el comunismo, a la vez que era un actor regional de primer orden por cuanto fue miembro fundador del Movimiento de los No Alineados y pasó a formar parte de la Organización de la Conferencia Islámica y de la Asociación de las Naciones del Sudeste Asiático.

En el discurso nacionalista para la formación del Estado de Indonesia se recreó en el imaginario colectivo el concepto de la Gran Indonesia a partir de los reinos de Srivijaya y Majapahit, los cuales se desarrollaron desde el Siglo VII al Siglo XVI. Estos reinos, que en los momentos de su mayor expansión se asemejaban más a imperios, constituyeron los antecedentes más destacados de la denominada integridad territorial indonesia.

La anexión indonesia se hizo bajo los argumentos de la necesidad de preservar la integridad territorial, puesto que la isla de Timor hacía parte de la Gran Indonesia (que había sido colonizada por potencias europeas) y había sido dividida en Timor Dili y Timor Kupang, pero que en realidad correspondían a un solo pueblo, una isla (Made, 2010). Otro de los antecedentes de la denominada integridad territorial consistió en que existía la amenaza de que se formara un foco comunista en Timor Oriental, el cual se manifestaba con el Fretilin y que podía contar con apoyo de la China maoísta a través de la Embajada china en Canberra (CAVR, 2005, Parte 3, 66-70).

No hay claridad sobre el hecho de que el Fretilin contara con apoyo extranjero, lo cierto fue que tuvo algunos líderes que fueron adeptos al comunismo, en especial, de orientación maoísta. También había algunos líderes, como Nicolau Lobato, que era marxista cristiano, a semejanza del movimiento latinoamericano fundado en la denominada Teología de la Liberación. Sin embargo, no se puede colegir que el comunismo era la ideología adoptada oficialmente por la organización. De por sí, es más cercano a la realidad señalar que la orientación del Fretilin era de centro izquierda, semejante a un partido social demócrata insurgente en busca de la independencia nacional (CAVR, 2005, Parte 3, 91-97).

Sobre lo que sí existe claridad es que el Fretilin se consolidó a partir de la invasión de Indonesia como el principal proyecto nacionalista timorense, cuya búsqueda de la independencia se reafirmó a partir de la identidad nacional, en donde jugó un papel fundamental el tétum como idioma nativo, pues reúne las 15 lenguas nativas, así como la simbología del término Maubere ${ }^{11}$. Sin duda, el factor lingüístico fue uno de los elementos clave que sustentaron el imaginario de la nación

${ }^{11}$ Maubere hace referencia al hombre timorense común, aquel campesino descalzo que no poseía papeles y que era analfabeto. Esta tipología correspondía al 90\% de la población timorense, lo cual convirtió el término Maubere en símbolo de identidad partidista, que lo diferenciaba de las demás organizaciones políticas, en particular, con el UDT (CAVR, 2005, Parte 3, 89-90). 
timorense (CAVR, 2005, Parte 3, 91-97). Cabe destacar que la lucha contra el alto analfabetismo de la población fue uno de los aspectos esenciales dentro del programa social del Fretilin, pues el índice era aproximadamente del 93\% para la época anterior a la invasión (Taylor, 2001, p. 215).

\subsection{La negación de una nación y la libre determinación}

La construcción independiente de la nación timorense durante la época de la anexión indonesia se incrementó de manera dramática, lo cual corrió de forma paralela al proceso de resistencia y fortalecimiento del Fretilin. Indonesia no tuvo mayores problemas, desde el punto de vista militar, para anexar a Timor Oriental y convertirla en su provincia número 27. El problema crucial para el gobierno de Yakarta fue el de derrotar el movimiento de resistencia timorense, así como lograr su incorporación dentro de la identidad nacional indonesia. Si bien, en los primeros años de la lucha militar por controlar la totalidad del territorio el ejército indonesio estuvo cerca en varias ocasiones de derrotar a la guerrilla del Fretilin, esta situación cambió para la década de 1980 y 1990.

La presencia militar indonesia en Timor fue alta, osciló entre 30.000 y 40.000 soldados, y se destacó su cuerpo de élite conocido como Kopassus. Las iniciativas del gobierno de Yakarta, desde un principio, se centraron en la consolidación del dominio territorial a través del ejercicio de la fuerza y de diversas compañas militares (CAVR, 2005, Parte 3, 223-376; Taylor, 2001, p. 216):

- «Operación Seroja, Fase Lotus» (1975-1977): abarcó la preparación ${ }^{12}$ y realización de la invasión a Dili, así como el posterior proceso de pacificación.

- «Operación Seroja, Fase II (1977-1979), también denominada como «Cerco y aniquilación». Para marzo de 1979 se declaró el territorio de Timor como pacificado, luego de haber capturado o abatido a líderes clave del Fretilin, tal como sucedió con la muerte de Nicolau Lobato. La población civil fue forzada a su desplazamiento hacia las montañas del interior; esta operación es catalogada como la más grande tragedia humana en la historia de Timor Oriental (CAVR, 2005, Parte 3, 321).

- Operación Seguridad (Operasi Kemanan) (1979-1981): aplicó la estrategia de fence of legs a través de la denominada táctica de kikis, la cual había sido aplicada en Indonesia con resultados positivos. Esta táctica consistió en movilizar en diversas marchas a cerca de 50.000 timorenses civiles a través del territorio de la isla para envolver militarmente a los grupos de insurgentes que estaban resguardados en las montañas. La operación fracasó, pues la población no apoyó al ejército indonesio y, por el contrario, generó una reacción en contra del mismo.

${ }^{12}$ Los ejercicios preparatorios a la invasión realizados por las tropas indonesias, los cuales contaron con seguimiento y apoyo de los servicios de inteligencia de Estados Unidos y Australia, fueron conocidos como Operación Flamboyan. 
Lejos de desarrollar un proceso de asimilación cultural, social y étnico de la población timorense como una de las 27 provincias del Estado de Indonesia, la brutal represión militar provocó el efecto inverso. Ese proyecto de comunidad imaginada indonesia, forjado por la población javanesa como grupo dominante, con gran esfuerzo desde su descolonización, no fue incluyente para los timorenses, quienes de manera progresiva percibieron que no eran iguales al resto de grupos que integraban la nación indonesia.

Ello permitió redimensionar elementos como la lengua (tétum y portugués), las costumbres, el pasado ancestral y tribal, la religión (la población se convirtió al catolicismo de manera masiva) ${ }^{13}$, la herencia colonial, entre otros, para fortalecer el sentido de identidad, lo cual configuró un sentimiento de otredad frente a Indonesia y, con él, se fortaleció la opción de la libre determinación timorense.

\subsubsection{Derecho de los pueblos a la libre determinación}

El derecho a la libre determinación se ha erigido en un principio básico internacional, pues es un derecho inalienable de todos los pueblos. Las Naciones Unidas, a través de la paradigmática Resolución 3382 (XXX) del 10 de noviembre de 1975:

(...) reafirmó el derecho de los pueblos a la libre determinación, a la soberanía nacional y a la integridad territorial, y de la rápida concesión de la independencia a los países y pueblos coloniales como condiciones para el disfrute de los derechos humanos y reafirmó la legitimidad de la lucha de los pueblos por la independencia, integridad territorial y liberación de la dominación colonial y extranjera por todos los medios, incluida la lucha armada. (Monroy, 2002, p. 241).

El principio a la libre determinación supone, para un pueblo colonial, el derecho a ser consultado, a expresar libremente su opinión sobre cómo desea conformar su condición política y económica y el derecho a convertirse en un Estado soberano e independiente. La autodeterminación de los pueblos tiene incidencia en el marco de los derechos humanos, en la medida en que otorga libertad y le permite al pueblo vivir y desarrollarse libremente. También existe la aplica-

\footnotetext{
${ }^{13}$ La labor de Monseñor Martinho Costa Lopes y, posteriormente el Obispo Carlos Filipe Ximenes Belo, permitieron que la labor de la Iglesia Católica durante el conflicto no fuese contemplativa sino que fuese activa en denunciar los abusos cometidos por las tropas indonesias. Los timorenses percibieron, después de la invasión, que los jerarcas de la religión católica eran solidarios con su problemática y les brindaban protección, bajo un sentido de santuario y supervivencia. De allí que no sea coincidencia que para 1973 sólo el $28 \%$ de la población era católica, mientras que en 1980, más del $80 \%$ de la población se había convertido al catolicismo. Por su labor, el Obispo Ximenes Belo sería galardonado con el Premio Nobel de Paz. (CAVR, 2005, Parte 3, 397-399).
} 
ción de este principio al interior de los Estados ya constitutivos, refiriéndose al derecho a la participación democrática por parte de los ciudadanos en los asuntos públicos, sin exclusiones ni distinciones basadas en el origen étnico o las creencias u opiniones.

El panorama para la libre determinación timorense comenzó a aclararse a partir de una serie de sucesos históricos. La caída del muro de Berlín y la visita del Papa Juan Pablo II a Dili, fueron dos eventos que cerraron la década de 1980 con vientos de cambio para el mundo y, en particular, para los timorenses. Adicionalmente, tres acontecimientos marcaron la década de 1990 para que se gestara la autodeterminación como un proceso irreversible:

a) La masacre del Cementerio de Santa Cruz: Ocurrió el 12 de noviembre de 1991, fue filmada por el periodista Max Stahl ${ }^{14}$ y difundida internacionalmente; este hecho generó un impacto en la comunidad mundial acerca de la violación de los derechos humanos por parte de Indonesia. La masacre sucedió en medio de los actos preparativos para el recibimiento de una delegación del Parlamento portugués; esta delegación probablemente se iba a reunir con el líder del Fretilin, Xanana Gusmão. La visita fue cancelada después del asesinato de Sebastião Gomes, quien era uno de los cuadros de la comitiva de recibimiento del Fretilin. Durante las exequias de Gusmão y, aprovechando la llegada de un delegado especial de las Naciones Unidas, se realizó una demostración masiva de rechazo a este asesinato, que transcurrió de manera pacífica, pero que posteriormente acabó en un baño de sangre. Inicialmente se calcularon 14 personas muertas, pero se estima que fueron aproximadamente 200 muertos. (CAVR, Parte 3, 475-486).

b) La captura de José Alexandre Xanana Gusmão en 1992, lo cual lo convirtió en una especie de Nelson Mandela en este conflicto. La captura de Gusmão fue el más importante golpe que Indonesia le propinó a la resistencia timorense, pero a la postre lo convirtió en un ícono que le reportó visibilidad y apoyo internacional a la causas de la autodeterminación timorense. Xanana permaneció recluido en la prisión de alta seguridad de Cipinang, en Yakarta. (CAVR, Parte 3, 487-488). Posteriormente, sería elegido presidente de Timor-Leste.

c) Otorgamiento en 1996 del Premio Nobel de la Paz al Obispo Carlos Filipe Ximenes Belo y a José Ramos-Horta. En el discurso de presentación de estos premios, se señaló que:

(...) el conflicto en Timor Oriental ha sido Ilamado «el conflicto olvidado» (...) Rara vez el cinismo de la política mundial había sido más claro (...) Este año dos premios Nobel de la Paz, Carlos Filipe Xiemnes Belo y José RamosHorta, han trabajado incansablemente y con gran sacrificio personal por su pueblo oprimido. En condiciones sumamente difíciles, han preservado su humanidad y la fe en el futuro. (CAVR, Parte 3, 502-506, traducción libre).

14 Periodista británico cuyo nombre original es Christopher Wenner. 


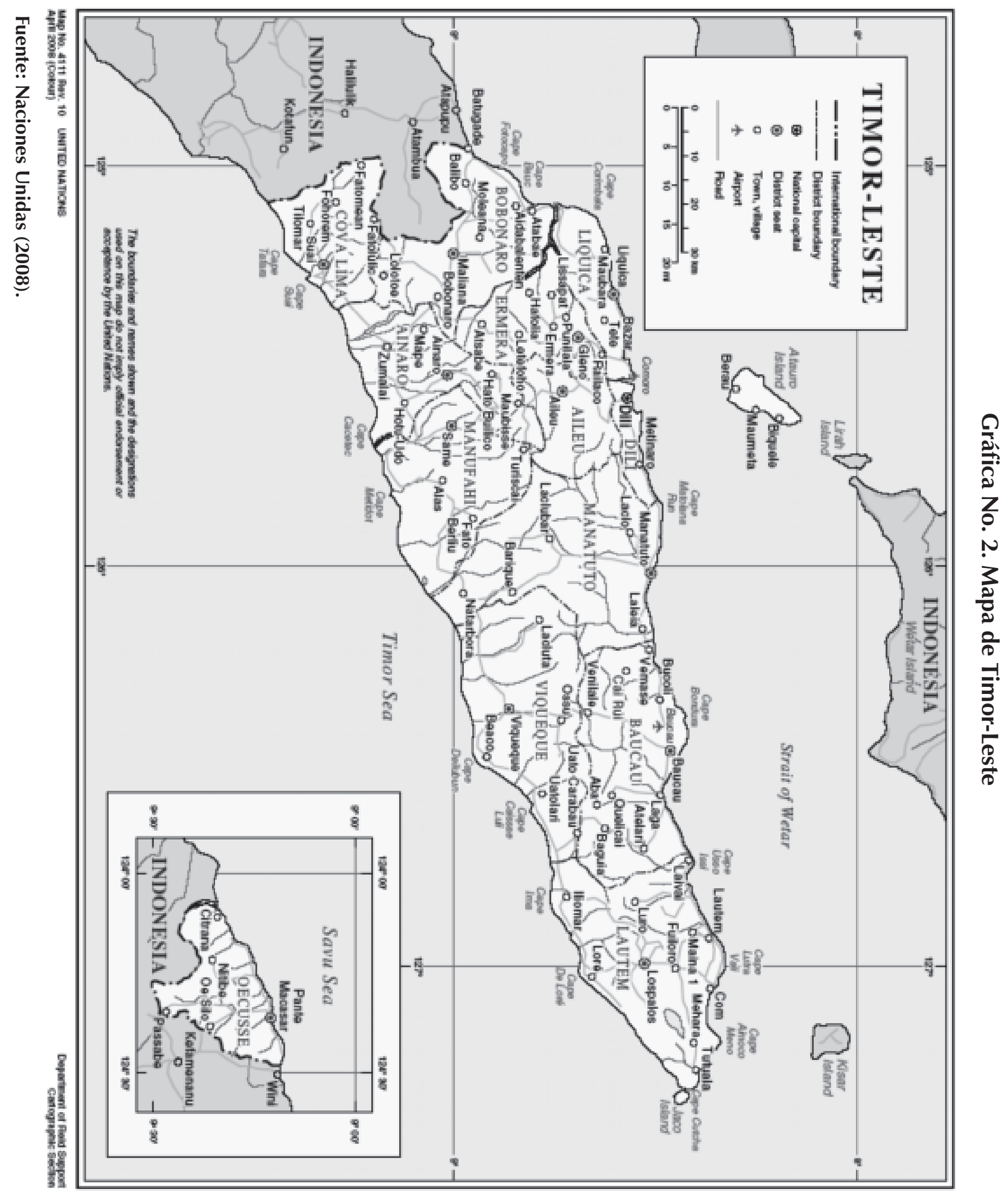




\section{TIMOR-LESTE COMO ESTADO FALLIDO}

Desde la perspectiva clásica, un Estado nación es reconocido como tal cuando posee un gobierno que ejerza control efectivo sobre un territorio determinado y la población que en él se asienta. Así mismo, la Convención de Montevideo de 1933 sobre los Derechos y Deberes de los Estados, añadió un nuevo requisito, que tiene que ver con la capacidad para relacionarse con otros sujetos del derecho internacional.

En el caso de Timor-Leste estos elementos conceptuales han sido esenciales, en particular el que se refiere a la legitimidad alcanzada a partir del reconocimiento dado por la comunidad internacional. Timor Oriental, al ser catalogado por mucho tiempo como un conflicto de baja intensidad, no ha jugado un papel de primer orden en la agenda internacional. Durante muchas décadas este conflicto no hizo parte de la política exterior de las principales potencias mundiales o regionales, por lo que fue olvidado en el contexto internacional.

Solo hasta que se dio una efectiva presión internacional, Indonesia cedió al proponer un referéndum para determinar si los timorenses deseaban continuar bajo el dominio del gobierno de Yakarta con una autonomía limitada. Ante este panorama, las Naciones Unidas iniciaron la preparación del censo y la consulta electoral. Para ello, la Organización autorizó el 11 de junio de 1999 el establecimiento de la Misión de Naciones Unidas en Timor Oriental (UNAMET), según lo dispuesto por la Resolución 1246 (Jacobson, 2006, p. 35).

Las elecciones se celebraron el 30 de agosto de 1999 con la participación del 98\% del censo electoral, donde la propuesta de la autonomía fue rechazada por un margen de $78,5 \%$ de votos, contra $21,5 \%$ que la apoyaron.

Las represalias de las tropas indonesias y las milicias proindonesias ocurridas después de conocidos los resultados del referéndum de 1999, dejaron aproximadamente 1.500 muertos y la mitad de la población desplazada, esto es, cerca de 550.000 personas. Así mismo, fue destruida el $70 \%$ de la infraestructura y el $100 \%$ de la red eléctrica del país (Jacobson, CAVR, Kingsbury y Roosa).

La UNAMET fue impotente para frenar esta enorme ola de violencia, debido a la falta de previsión de un escenario de estas características y al control militar del ejército indonesio en el país, el cual había sido una condición establecida por Yakarta. Ello planteó un gran reto para la comunidad internacional que la comprometía a brindar una mayor asistencia y atención a esta nación a la que el derecho al ejercicio de su libre determinación se había dilatado por 25 años.

Con base en el Capítulo VII de la Carta de las Naciones Unidas y en su condición de territorio no autónomo, Timor Oriental tuvo una administración civil internacional estructurada en los siguientes ejes: 
a) Establecimiento de operaciones multidimensionales con componentes civiles y militares.

b) Preservación de la soberanía y la integridad territorial.

c) Inclusión de propósitos sociales por parte de la sociedad internacional, además de los tradicionales fines cifrados en la seguridad y protección de los derechos humanos.

d) Responsabilidad de administrar ciertos territorios, con empoderamiento en el ejercicio de las ramas ejecutiva, legislativa y judicial. (Zervaki, 2008, p. 12).

El 30 de agosto de 2001 se realizó una consulta popular en Timor Oriental para elegir la Asamblea Constituyente, la cual quedó integrada por 88 representantes con la finalidad de redactar la primera Constitución de este naciente Estado. El 22 de marzo de 2002 la Asamblea Constituyente promulgó la Carta Magna, siendo elegido el 14 de abril de 2002 Xanana Gusmão como su primer presidente. Un mes después, el 20 de mayo, el Estado definió el parlamentarismo como su sistema de gobierno (Jacobson, 2006, pp. 36-37).

\subsection{La concepción de Estado fallido}

Timor-Leste está conmemorando diez años del referéndum que hizo irreversible su proceso de independencia, lo que equivale a una vida independiente de una década de construcción de Estado, de creación de instituciones y de experimentación de participación política efectiva. Sin embargo, las características propias del Estado de Timor han evidenciado la complejidad del proceso, más aún con los indicadores de medición internacional que han ubicado al joven Estado, para el año 2010, en el puesto 144 entre los países más pobres del mundo y de la misma forma ha sido catalogado en la medición de los últimos cuatro periodos entre los 25 primeros del índice de estados fallidos (Fund for Peace, 2010), lo que crea una percepción de Estado-problema en la comunidad internacional y le genera un lastre al ser categorizado de esta manera.

La concepción de Estado fallido se constituye como una fórmula de categorización de los estados que se alimenta de un heterogéneo espectro de problemas y sobre el cual no se ha generado una teorización amplia, por lo que se convierte en un concepto difuso. Su aplicabilidad frecuente en el escenario internacional se debe al orden post 11/S, en el cual la lucha contra el terrorismo, emprendida por el gobierno de Estados Unidos contra los estados que soportaban las organizaciones terroristas, inició la aplicación de terminología de denominación como weak states, rogue states, collapsed states y failed states.

Si bien las concepciones de los autores son diversas, lo que se puede inicialmente sacar en claro es que un Estado fallido o fracasado no puede resolver sus problemas por sí mismo, por lo que genera la necesidad, incluso si no lo manifiesta así, de una intervención extranjera (Sur, 2005, p. 91) que le dé apoyo en la construcción de instituciones estatales fuertes y permanentes, que garanticen la participación política efectiva, y que mejore sus indicadores de prestación de servicios básicos. 
El Estado fallido presenta características amplias en las que el gobierno es ineficiente para cumplir con las funciones básicas para las cuales ha sido constituido, por cuanto no articula los intereses de la población ni da respuesta a sus necesidades. No cumple así con los requerimientos esenciales para el trabajo estatal: un aparato burocrático apolítico que legitime la neutralidad de las instituciones de gobierno y que mantenga el orden social (Chesterman, 2005, p. 2).

El concepto de Estado fallido no es estático, pues se sustenta en una serie consecutiva de circunstancias que se manifiestan en un proceso de caída de los estados. Es así como existen estados fuertes, con solidez institucional, formación estatal antigua, indicadores sociales y económicos óptimos, con tradición democrática y vida independiente ininterrumpida. Desde este punto ideal, los estados pueden convertirse inicialmente en estados débiles, y al profundizarse sus problemas internos, en Estados fallidos. Finalmente, cuando la situación se torna insostenible en un periodo determinado y el caos estalla a partir de un evento puntual, se denomina Estado colapsado (Rotberg, 2003, pp. 4-9).

La caracterización del Estado fallido se puede realizar desde ejes básicos que están inevitablemente relacionados y muestran con claridad el fracaso en la realización de la tarea estatal. El primero de ellos se refiere a la incapacidad del gobierno para proveer los bienes públicos básicos. De estos, se destaca la seguridad: el control efectivo de las fronteras (en muchas ocasiones que no están claramente definidas) ante amenazas externas, amenazas domésticas y la incapacidad de crear las instancias de resolución de conflictos entre la población sin recurrir a la violencia (Rotberg, 2003, p. 3). Las fuerzas armadas están altamente politizadas y dependen directamente del control del gobierno establecido.

Esta falla en la seguridad se manifiesta en violencia interna, debido a que el Estado es incapaz de ejercer el monopolio del uso legítimo de la violencia. Esta violencia (Oxford Analytical, 2009, p. 1) se caracteriza por ser continua y sistemática, generalizada y con presencia en grandes partes del territorio, incluso llegado a estadios en que el gobierno establecido pierde el control de aéreas específicas del territorio nacional. Se crean divisiones en la población y los grupos antigobiernistas que utilizan la violencia con fines políticos se combinan con la proliferación de organizaciones criminales que se benefician de la situación general para la creación de redes delictivas internacionales y para el fenómeno del narcotráfico.

De la misma forma, el Estado fallido es incapaz de proveer y mantener los bienes políticos. Las instituciones son defectuosas y se encuentran bajo el control directo del ejecutivo, haciendo indefinida la división entre los poderes públicos. Existen grandes problemas para la participación democrática libre y abierta y para garantizar los derechos humanos y civiles. Además, no existe un sistema judicial efectivo que garantice la resolución pacífica y neutral de las disputas civiles.

En cuanto a los bienes económicos, se destaca la pobreza generalizada y la ausencia de infraestructura. Además, las finanzas estatales se encuentran colapsadas debido al alto grado de 
corrupción y a los gastos en seguridad. La infraestructura económica deficiente, incluso inexistente, impide la explotación de los recursos, por lo que son multinacionales extranjeras las que intervienen con este fin, agregando nuevas dinámicas a la situación. De igual forma, es precaria la situación de servicios de salud y educación.

El segundo eje, consecuencia del primero, se refiere a la pérdida de legitimidad del Estado. En un Estado fallido es claro que la obediencia de la población se debe no a las reglas establecidas, sino a la persona que ocupa el cargo de autoridad (Chesterman, 2005, p. 3). El poder del gobierno no hace presencia en la totalidad del territorio, la autoridad central limita su presencia a la capital y las ciudades más grandes.

Esta pérdida de legitimidad, y el consecuente proceso de fracaso o falla estatal, es justificado por la presencia de una herencia del colonialismo (Chesterman, 2005, p. 17). La construcción de límites caprichosos por parte de las potencias colonizadoras por encima de las formas naturales y de las divisiones entre los pueblos nativos, derivan en la actualidad en la proliferación de estados poco cohesionados socialmente, con problemáticas étnicas o religiosas, que son económicamente frágiles, y con un reducido desarrollo económico e infraestructura deficiente. También es posible identificar la presencia de gobiernos dictatoriales que por conductas autoritarias manejan el poder legitimado en la fuerza y con altos grados de corrupción tampoco generan el desarrollo histórico necesario para la consolidación estatal.

\subsection{Timor-Leste: ¿Estado fallido?}

La complejidad comprensiva que implica el término de Estado fallido genera problemas, como la sistematización en la identificación de alertas de caída en los indicadores, pues las categorizaciones utilizan diversidad de variables para abarcar una situación de tratamiento sensible y difuso. Existen clasificaciones de organizaciones de todo tipo, las cuales, según sus mediciones, identifican y establecen la puntuación según criterios propios para la valoración del éxito o fracaso de los estados. Aunque el riesgo implícito de este tipo de mediciones es su grado de subjetividad.

Una de las mediciones más populares a nivel mundial es la realizada anualmente por Fund for Peace y la revista Foreign Policy. Como toda medición, es objeto de análisis y críticas. Por ejemplo, Manjikian considera que el rótulo de Estado fallido es sinónimo de Estado enfermo que sugiere que la comunidad internacional lo identifique, caracterice y lo someta a observación, pues puede ser el foco de un posible contagio para el resto del mundo.

De cualquier forma, es importante observar cuáles son los criterios utilizados para generar esta clasificación de estados fallidos. Para la medición de Foreing Policy se tienen en cuenta los aspectos sociales, económicos y político-militares, como se detalla en la tabla No. 1. 
Tabla No. 1

Indicadores para la medición de estados fallidos

\begin{tabular}{|c|c|c|}
\hline \multicolumn{3}{|c|}{ INDICADORES SOCIALES } \\
\hline 1 & Presiones Demográficas & $\begin{array}{l}\text { Presiones sociales derivadas del crecimiento de la po- } \\
\text { blación. (Alimento, trabajo, posesión de tierra y par- } \\
\text { ticipación). }\end{array}$ \\
\hline 2 & Refugiados y desplazados & $\begin{array}{l}\text { Grandes movimientos poblacionales debido a ame- } \\
\text { nazas derivadas de la inseguridad y la violencia. }\end{array}$ \\
\hline 3 & Agravios colectivos y paranoia social & $\begin{array}{l}\text { Injusticias provenientes de hechos condenables tra- } \\
\text { tados con impunidad por parte del Estado. }\end{array}$ \\
\hline 4 & Migraciones y fugas crónicas & $\begin{array}{l}\text { Fuga de talentos hacia países cercanos, incrementando } \\
\text { población en el exilio. }\end{array}$ \\
\hline \multicolumn{3}{|c|}{ INDICADORES ECONÓMICOS } \\
\hline 5 & Desarrollo económico desigual & $\begin{array}{l}\text { Según el patrón de participación en el consumo, tra- } \\
\text { bajo, nivel de educación y mortalidad infantil. }\end{array}$ \\
\hline 6 & Fortaleza de la economía & $\begin{array}{l}\text { Crecimiento del PIB, tasa de desempleo, estabilidad } \\
\text { monetaria, déficit, deuda, inversión, formalidad y se- } \\
\text { guridad social. }\end{array}$ \\
\hline \multicolumn{3}{|c|}{ INDICADORES POLIITICOS / MILITARES } \\
\hline 7 & Deslegitimación del Estado & $\begin{array}{l}\text { Corrupción, favoritismo hacia grupos de interés, falta } \\
\text { de confianza en las instituciones públicas, e incapaci- } \\
\text { dad del Estado para financiarse. }\end{array}$ \\
\hline 8 & Deterioro de los Servicios Públicos & $\begin{array}{l}\text { Falta de capacidad para atender las necesidades de } \\
\text { la población. }\end{array}$ \\
\hline 9 & Violación de los Derechos Humanos & $\begin{array}{l}\text { Presencia de dictaduras, autoritarismos o militares en } \\
\text { el poder, atentando contra la democracia y el Estado } \\
\text { de Derecho. }\end{array}$ \\
\hline 10 & Aparatos seguridad & $\begin{array}{l}\text { Organización de las fuerzas de seguridad del Estado. } \\
\text { Surgimiento de cuerpos paralelos de seguridad. }\end{array}$ \\
\hline 11 & Grado de división de las élites & $\begin{array}{l}\text { Separación de las élites, falsos nacionalismos o pre- } \\
\text { eminencia de intereses subversivos. }\end{array}$ \\
\hline 12 & Intervención externa & Intervención de agentes externos al Estado. \\
\hline
\end{tabular}

Elaboración propia, tomando como base datos de Fund for Peace (2010). 
Cada una de las variables se evalúa en una escala de 1 a 10, en donde 10 representa una mayor intensidad del factor, lo que implica una mayor amenaza a la estabilidad política del Estado. Una vez calificada cada una de las variables, el índice se obtiene de la suma de los 12 elementos; si se tiene una evaluación muy alta, se considera que el Estado tiene un grado elevado de carencias.

Para la medición de 2010, el ranking ubica al Estado de Timor-Leste en el puesto número 18, con un puntaje total de 98.2, lo que le representa una caída de dos puestos desde la medición del año inmediatamente anterior. Los indicadores más críticos, que representan una gran amenaza a la estabilidad del país, corresponden a la deslegitimación del Estado (9.1), al alto número de refugiados y desplazados (9.1), aparatos de seguridad (8.8) y la intervención extranjera (9.2).

En cuanto al tema de los desplazados y refugiados, la situación se hizo crítica en el periodo inmediatamente posterior al referéndum independentista de 1999, cuando las fuerzas de seguridad indonesias y las milicias opuestas a la independencia promovieron el saqueo y la violencia contra la población civil. Ello provocó un desplazamiento forzado masivo hacia el occidente de la isla y hacia el interior del país. Se calculó que fueron 290.000 personas refugiadas en los campamentos de Kupang y en la ciudad fronteriza de Atambua, donde las condiciones de vida eran precarias, mientras que el número de personas desplazadas aproximadamente fue de 250.000 (ACNUR, 2000, Capítulo 9).

Si bien la situación de los refugiados fue mejorando a principios de 2000, con el retorno de 130.000 personas a Timor-Leste, un importante número de refugiados aún permanece en Indonesia, principalmente de la provincia de Nusa Tenggara. Un agravante que se presentó de esta situación fue que en el año 2006 el gobierno indonesio dejó de financiar los campamentos al no reconocerles la calidad de refugiados (El Mundo, 2008, 7 de abril). En cuanto a los desplazados, el informe de 2009 de Amnistía Internacional contabilizó que su número ascendió a 40.000 personas, quienes se ubicaron en Dili y sus alrededores. Su situación es deplorable en materia de salubridad, servicios públicos y acceso a los recursos. (Amnistía Internacional, 2009).

En el tema de la autonomía del país es evidente que esta no se ha consolidado, pues ha requerido la participación de actores externos, donde se destaca la intervención de la Organización de Naciones Unidas. A partir de 1999, la ONU ha desplegado sus misiones en el territorio de Timor-Leste que han evolucionado con el transcurso de los años, adaptándose a las diferentes situaciones de la construcción estatal y a las necesidades coyunturales.

Inicialmente, entre junio y octubre de 1999, se estableció UNAMET (United Nations Mission in East Timor) con el objetivo claro de hacer seguimiento y organizar el referéndum para determinar la separación de Indonesia, además de conducirlo, verificarlo y supervisar el periodo transitorio que se daría tras la publicación de los resultados. La UNAMET fue sustituida por UNTAET (United Nations Transitional Administration in East Timor) desde octubre de 1999 hasta mayo 
de 2002, como una operación de mantenimiento de la paz, que además ejerció como autoridad administrativa en Timor Oriental durante el período de transición a la independencia.

Entre mayo de 2002 y mayo de 2005 se estableció la UNMISET (United Nations Mission of Support to East Timor) como una nueva misión de paz para prestar apoyo a la independencia de Timor Oriental, una vez fueran devueltas las responsabilidades operativas a las autoridades y se lograra la autosuficiencia. Posteriormente, durante el lapso de mayo de 2005 hasta agosto de 2006, UNOTIL (United Nations Office in East Timor) apoyó el desarrollo de las instituciones estatales (ONU, Departamento de Operaciones de Paz, 2010).

Ante las circunstancias de una crisis no solucionada, de violencia emergente y frágil institucionalidad, las autoridades gobernantes de Timor-Leste solicitaron a la ONU el establecimiento de una nueva misión que contara con fuerzas policiales para garantizar el orden. Fue así como se estableció UNMIT (United Nations Integrated Mission in Timor-Leste), para prestar apoyo al gobierno y a las instituciones, con miras a consolidar la estabilidad, fomentar una cultura de gobernanza democrática y facilitar el diálogo político. La UNMIT brinda soporte a la policía nacional y presta asistencia para la realización de un examen amplio de la función y las necesidades futuras del sector de seguridad (ONU, Departamento de Operaciones de Paz, 2010).

Es así como en Timor-Leste la intervención extranjera se hace evidente, desde la realidad manifiesta, de que el poder del gobierno, la estabilidad estatal y el orden público no pueden ser garantizados autónomamente por las instituciones constituidas para tal fin, por lo cual la presencia de la ONU es vital para asegurar la supervivencia estatal. No se ve en un futuro cercano un contexto propicio para la salida completa de la ONU, pues el mandato de UNMIT fue prorrogado hasta 2011, lo que demuestra el lento proceso de consolidación que el Estado de TimorLeste ha desarrollado.

\section{CONSTRUYENDO ESTADO NACIÓN}

\subsection{Consolidación de las instituciones}

Inicialmente la implementación del modelo democrático occidental representó para Timor-Leste un desafío de grandes proporciones, más que una forma de unificación nacional y de integración al proyecto de construcción del Estado, debido a que esta nueva institucionalidad creó una serie de conflictos que están en vía de solución.

Uno de los factores que ha influenciado la escasa institucionalidad en la creación del Estado nación es la ausencia de un periodo de transición democrática, por lo que el modelo gubernamental ha sido percibido por los timorenses como impuesto por la comunidad internacional. Esta situación ha hecho que las instituciones sean frágiles y estén en plena formación, con la responsabilidad 
de representar el poder del Estado aún cuando no estaban en condiciones de hacerlo (Graça, 2009, p.124). Se estableció un andamiaje estatal de instituciones propias independientes y un sistema democrático multipartidista y de separación de poderes. Sin embargo, la población no fue preparada para este cambio y los gobernantes tampoco fueron eficaces en su implementación.

Desde la proclamación de Timor-Leste, la independencia de los órganos de gobierno se relativizó. El ejecutivo, con alta influencia de los organismos internacionales, centralizó el poder bajo su mando, sustentado en el poder del FRETILIN, el cual detentaba absoluta mayoría en el Parlamento, debido a que la población tenía reparos sobre la idea de un sistema de varios partidos y la presencia del FRETILIN en el proceso de la lucha independentista le otorgó un lugar privilegiado en la mentalidad del pueblo (Gamero, 2005, p. 10). No existía confianza entre el gobierno central y los órganos subsidiarios, de allí que la centralización de decisiones fue absoluta, por lo que la funcionalidad del sistema no fue la esperada.

El pueblo ha tenido escasa educación cívica y electoral y, más bien, se le ha dado prioridad al proceso de votación como único elemento de significación democrática. Las instituciones todavía se encuentran lejanas de las realidades de la comunidad y no representan los intereses de los núcleos sociales, que siempre han buscado formas tradicionales de representación mucho más cercanas.

En cuanto al poder judicial, tampoco su aplicación ha sido satisfactoria. Ni los gobernantes ni la población consideran a las instituciones de justicia establecida como la forma legítima de solución de los conflictos (Engel, 2006, p.7). Fuera de la capital, la gran mayoría de los problemas son llevados ante tribunales tribales, donde los líderes tradicionales de la comunidad imparten una justicia paralela al gobierno establecido.

Lo anterior ha sido también consecuencia de la poca confianza que se tiene en los estamentos judiciales, en los que los crímenes de alto nivel, como las violaciones a los derechos humanos, no son condenados de manera ejemplarizante, otorgando castigos a los menos implicados en estas situaciones. El establecimiento de la Unidad Especial de Crímenes Graves, con la intervención insuficiente de jueces extranjeros y con la obstrucción manifiesta de Indonesia, es una muestra clara de la inoperancia de las instituciones judiciales (Rocamora, 2005, p. 180).

Hasta 2005, de las 392 personas implicadas en crímenes contra los derechos humanos, sólo 74 habían sido condenadas, mientras que los procesos contra las restantes se encontraban estancados y con los acusados fugados en territorio indonesio. Al parecer, existe un acuerdo no explícito de perdón y olvido respecto a las violaciones de derecho humanos cometidos por agentes estatales durante el periodo de la ocupación indonesia.

Entre los problemas más destacados en materia judicial, se ha evidenciado el insuficiente personal cualificado para ejercer en los tribunales de justicia y la confusión acerca de la normativa 
vigente, por cuanto el ordenamiento jurídico permitía la aplicación de normas indonesias elaboradas durante la época de la ocupación, normas timorenses (tanto de la nueva república como ancestrales) y las normas de origen internacional elaboradas por UNAMET.

Sin embargo, con el paso de los años, se ha evidenciado una paulatina consolidación de la organización institucional de Timor-Leste, aunque el proceso está lejos de ser completo. Se destacan aspectos positivos como, por ejemplo, la realización de las elecciones presidenciales y parlamentarias de 2007, que se convirtieron en un hito en la historia democrática de TimorLeste, pues fueron las primeras organizadas de manera directa por las autoridades timorenses con apoyo internacional. Dicha jornada electoral se realizó de manera exitosa en aspectos como el cumplimiento del cronograma, transparencia y seguridad, a pesar de la complicada situación tras la crisis de 2006 (Graça, 2009, p.125).

Las elecciones de 2007 dieron como resultado la designación de Ramos Horta como presidente, con 285.000 votos en la segunda vuelta. Así mismo, se eligieron los miembros del Parlamento con la presencia importante de cuatro partidos: FRETILIN (29\%), CNRT (24\%), ASDT/PSD (16\%) y el PD (11\%). A pesar de que el FRETILIN obtuvo el mayor porcentaje de votación, fue evidente la pérdida del poder absoluto que ostentaba desde la independencia. Timor-Leste se abrió así a un sistema multipartidista que crea el debate en la formación de gobierno y no está vinculado a una única fuerza.

Cabe resaltar la participación activa de la población en el proceso electoral, la cual llegó al 80\%, equivalente a 426.210 votantes, en 700 puestos de votación (McWilliam, Bexley, marzo de 2008, p. 66); además de la disminución considerable en el número de votos en blanco y votos anulados (Graça, 2009, p.136). Estos hechos han demostrado que la incipiente sociedad timorense ha empezado a encontrar una representación en los mecanismos de elección democrática establecidos para generar los cambios que el Estado necesita sin recurrir a la violencia.

Los resultados de las elecciones fueron aceptados por la población timorense y permitieron que los cambios en las figuras de gobierno se hicieran pacíficamente y sin intenciones de las partes de perpetuarse en el poder ni de bloquear los cambios determinados por los votantes. La sucesión del gobierno se realizó de manera pacifica, lo cual generó un ambiente de mayor convergencia entre el presidente, el parlamento y las demás instituciones de gobierno.

Sin embargo, aún persisten diversos problemas, sobre todo en los aspectos económicos. Durante los años 2007 y 2008 se dio un crecimiento económico superior al 10\%; los índices combinados de desempleo y subempleo fueron superiores al 70\%, y cerca del 42\% de la población todavía vive por debajo de la línea de la pobreza. Por su parte, los servicios públicos domiciliarios y las redes de comunicación son deficientes, mientras que el analfabetismo fue del 57\% (Fund for Peace, 2010). Si bien es cierto que estos retos van mas allá de la construcción y consolidación de las instituciones estatales, también es cierto que no encontraron una solución con la simple instauración de elecciones libres. 


\subsection{Construcción de la nación timorense}

Para Timor-Leste la construcción de nación es una tarea que representa dificultades importantes y que inicia desde su misma identificación nacional. Es claro que a lo largo de su vida estatal independiente, la identidad nacional o los sentimientos nacionalistas han sido poco claros e indefinidos. En tiempos pasados, la nación se había edificado sobre las instituciones locales tradicionales, en especial la uma builk o casa sagrada, que constituían la referencia sociopolítica integradora de la población. De la misma forma, bajo la ocupación portuguesa e indonesia, la identidad de la población se construyó en torno a la búsqueda de la independencia y la creación del Estado de Timor-Leste (Canas, 2009, p. 23). Sin embargo, la concreción del sueño independentista sacó a la luz, posteriormente, los bajos niveles de cohesión y la debilidad de un proyecto homogéneo de construcción estatal.

Estas problemáticas se potenciaron a partir de las decisiones tomadas bajo la administración transitoria de la Naciones Unidas, que marcaron el proceso posterior de vida independiente y las dinámicas recientes de la construcción de nación. Fue así como la actuación de la ONU estuvo fuertemente centralizada en Dili. Las instituciones creadas mostraron un alcance muy limitado y su presencia, fuera de la capital, era mínima, circunstancia que condujo a que la mayoría de la población se ubicara en áreas rurales, alejadas de su influencia.

Así mismo, las instituciones fueron instauradas en Timor-Leste partiendo de la convicción de una construcción desde el inicio, donde todo estaba por instituir. En un inicio fueron infravaloradas las prácticas locales tradicionales que habían sido reprimidas en la ocupación indonesia, y que resurgieron con la independencia y con la imposición de los modelos occidentales democráticos (Boegue, Brown, Clements, Nolan, 2008, p.13). Paulatinamente, se ha retornado a las tradiciones locales y a los vínculos con los ancianos y guías espirituales, entidades no tenidas en cuenta para el proyecto de Estado timorense. El desconocimiento de las tradiciones y costumbres tribales puede acarrear que las instituciones no sean reconocidas como propias por la población y sea considerado un ente ajeno que no representa sus intereses y creencias (Tejada, 2010).

Además de la necesidad de retornar a las tradiciones ancestrales, ha existido la sensación social de una división geopolítica en el país, en términos de discriminación. La situación se generó en enero de 2006, cuando un grupo de 159 soldados firmaron un documento en el que protestaban por el trato desigual y discriminatorio al interior del Ejército. Para marzo del mismo año, 600 soldados (denominados como «Los solicitantes»), en su mayoría originarios de la parte oeste del país, desertaron de la institución. La situación se desencadenó a partir de las tensiones entre el Ejército (F-FDTL) y la Policía (PNTL), en donde ésta última apoyó a «Los solicitantes», estimulando cruentos enfrentamientos y revueltas. El desorden originado sólo pudo ser contenido con la presencia de las fuerzas internacionales de paz y la renuncia del primer ministro Alkatiri, acusado de distribución de armas entre la población civil (Simonsen, octubre de 2008, p.1-14). 
La crisis se mantuvo latente, al tener su episodio más dramático en febrero de 2008, cuando el mayor Alfredo Reinado, líder del grupo de «Los solicitantes», murió mientras comandaba una milicia que atentó contra el presidente Ramos-Horta y el primer ministro Gusmão. Con la caída de su líder, «Los solicitantes» iniciaron su rendición y desmovilización; este hecho motivó el surgimiento de bandas juveniles callejeras que han aumentado la inseguridad en las principales ciudades (Simonsen, octubre de 2008, p.1-14). De igual forma, las relaciones entre el F-FDTL y el PNTL están en proceso de normalización, con el agravante del malestar existente entre la población acerca de la indeterminada precedencia de las fuerzas de paz de la Naciones Unidas.

Esta serie de acontecimientos han configurado una relación asimétrica entre Dili y el resto del país, es decir, su hinterland. Este desfase se hizo palpable cuando surgió una rivalidad geográfica entre timorenses del este (Firaku o lorosae) y timorenses del oeste (Kaladi o loromanu) (Hicks, febrero de 2007, p.13-16). Dicha rivalidad está basada en divisiones artificiales creadas por los portugueses e indonesios, quienes alentaron las divisiones internas para provecho propio, pues no existían diferencias étnicas o religiosas sustanciales (Kingsbury, Leach, 2007, p. 355-358).

Si bien esta división era palpable en la sociedad timorense desde principios del Siglo XX, nunca fue determinante para las relaciones al interior de la isla. Fue sólo hasta después de la declaración de la independencia cuando algunos sectores resaltaron cómo los líderes de la guerrilla procedían de la parte este, y cómo las principales actividades de la resistencia tuvieron lugar en el área oriental de Timor.

Dentro del proceso de construcción de la nación y el afianzamiento de la identidad de los habitantes de Timor-Leste, se ha destacado el idioma y el lenguaje como aspectos clave. Si bien el lenguaje nacional es el tétum, y el idioma oficial es el portugués, el país es un mosaico multilingual complejo, pues hay 12 lenguas nativas que se subdividen en más de 35 dialectos y subdialectos ${ }^{15}$.

El portugués es hablado de manera casi exclusiva en la capital, pero no es el idioma que represente a la nación timorense (Hicks, febrero de 2007, p.13-16). La instauración de la lengua portuguesa no fue una prioridad para los colonizadores desde su llegada a mediados del Siglo $\mathrm{XVI}$, donde solamente los misioneros portugueses intentaron, por medio de la alfabetización y

15 El grupo de lenguas austronesias son: (1) Tétum, que se habla en Dili, Suai, Viqueque y en la frontera con Indonesia; (2) Galoli, que es hablado en Dili, en Manatuto y Laclubar; (3) Mambai, hablado al sur de Dili y en Aileu, Ermera, Ainaro; y (4) Tokodede, hablado en Liquica. El grupo de lenguas no austronesias son: (5) Bunak, hablado en Bobonaro y en la frontera con Timor occidental; (6) Kemak, hablado en las regiones occidentales; (7) Makassai, hablado en Baucau y al este de Viqueque; (8) Dagada, hablado en Lautem; (9) Idate, hablado en las regiones centrales del interior; (10) Kairui, hablado en Laleia; (11) Nidiki, hablado en las tierras centrales del sur; y (12) Baikenu, hablado en Ambenu. (Donohue \& Grimes, 2008). 
de la religión católica, ensañar su idioma a los nativos. De allí que se estime que más del 90\% de la población no maneja el portugués como idioma (Kingsbury, Leach, 2007, p. 355-358).

Sin embargo, no se puede desconocer que el idioma portugués se ha constituido, en la historia de Timor, en un eje importante por su valor simbólico (Ruak, 2001). El portugués se convirtió en la lengua de la resistencia en los tiempos de la ocupación de Indonesia, pues buena parte de las comunicaciones se hacían en este idioma, aunque las autoridades de Indonesia habían prohibido su uso. Los nombres de las ciudades, edificios públicos, nombres y apellidos de la población son, en su gran mayoría, en portugués (Albarran, 2001). Así mismo, el sistema judicial y el servicio civil manejan este idioma, limitando de manera ostensible el acceso real a la justicia.

El amplio desarrollo del portugués como lengua es un factor determinante para que sea considerado como uno de los dos idiomas oficiales de los timorenses. Mientras que el tétum surgió como un medio lingüístico intermediario que permitió la comunicación entre la gran cantidad de dialectos y lenguas nativas, su desarrollo fue espontáneo y las condiciones históricas impidieron su consolidación como lengua moderna, generando claros vacíos en la comunicación escrita y sobre las reglas ortográficas. Así mismo, el tétum carece de terminología técnica y científica, por lo cual este tipo de desarrollos deben ser en portugués. Una tarea pendiente, para que el tétum se constituya definitivamente como la lengua que facilite la cohesión e identidad nacional, consistirá en alfabetizar a la población en el tétum, teniendo como prioridad la construcción gramatical del idioma (Costa, 2001).

Timor-Leste requiere reconstruir su propia concepción de nación, dejando de lado algunas de las ataduras occidentales que han sido incluidas a partir de la intervención de las operaciones de paz de las Naciones Unidas. En este sentido, los países occidentales deben entender que imponer stricto sensu su visión institucional, cultural y política en el joven Estado está generando efectos negativos en la unidad nacional y en el desarrollo del país. Se deben hacer concesiones, respetando el adat, es decir, las tradiciones o derecho consuetudinario y procurando el resurgimiento de las identidades locales, en plena coherencia con el proyecto nacional de Estado (Hicks, febrero de 2007, p.13-16). En tal sentido Durand señala que:

El manejo de (...) la diversidad y las disparidades (...) son una de las más complejas tareas que le espera a los líderes de Timor Oriental en el futuro (...) Lo que sigue ahora es establecer la independencia para reconciliar la diversidad de la herencia y las aspiraciones de una mejor vida que deben ser reforzadas después de un cuarto de siglo de penurias (Durand, 2006).

La formación de una narrativa nacional histórica timorense está en proceso. Se están revitalizando conceptos de alta carga nacionalista. Uno de ellos es la identidad Maubere, término que se refiere al timorense oriental auténtico, tanto étnica y culturalmente, que no tuvo lazos de parentesco con la sociedad indonesia y no fue proclive a la anexión de aquel país. Otro elemento que 
ha resurgido ha sido el adat, propio de cada suku (pequeños distritos o focos de dominio tribal organizados por lazos parentales). Esto ha permitido revitalizar la memoria histórica, reconociendo el legado de sus ancestros (Hicks, febrero de 2007, p. 14). Tareas como las anteriores requieren grandes trabajos ante la carencia de estructuras que revivan la memoria histórica. Por ejemplo, es ilustrativa la destrucción del Museo de Historia Nacional, el cual está en reconstrucción, pues parte de sus reliquias nacionales se encuentran actualmente en Indonesia.

\subsection{Identidad e intervención extranjera}

El dilema de Timor-Leste sobre la construcción de Estado se suscribe entre el proyecto de liberación y el juego bajo las reglas del sistema internacional, disyuntiva que ha generado tensiones respecto a la unidad nacional. Se han hecho muchas concesiones en materia de política exterior en temas como la explotación de los recursos naturales y la delimitación de las fronteras, la instauración de la institucionalidad democrática y económica occidental y los mecanismos para juzgar los crímenes cometidos por oficiales militares durante la ocupación de Indonesia (Webster, 2007, p. 581-591).

Por un lado, surge una situación que es común denominador para los estados en vías de desarrollo o de reciente instauración: la intervención de los organismos económicos internacionales. El Banco Mundial (BM) y el Fondo Monetario Internacional (FMI) constituyen también parte importante de la integración de Timor-Leste en las dinámicas internacionales. La necesidad inmediata de un flujo de ingresos para la construcción de la infraestructura del país y las complicaciones para obtener estos ingresos de la explotación de los recursos naturales, crean la necesidad de recurrir a financiación internacional y a caer en ciclos de intereses, que han conducido a que Timor-Leste, en el periodo entre 2003 y 2005, haya tenido un déficit entre 84 y 91 millones de dólares (Gamero, 2005, p.12).

Además, el BM ha sido el administrador de gran parte de las donaciones internacionales que los estados cooperantes han realizado para apoyar la construcción timorense, lo que ha producido una importante influencia en las decisiones gubernamentales y a determinar la agenda estatal en temas clave.

Una situación similar se ha producido con el FMI, debido a que Timor-Leste, al ingresar en el escenario económico internacional, ha sido sujeto de la imposición de las políticas de libre comercio sin que se hayan tenido en cuenta sus realidades internas. Esta situación ha provocado complicaciones para la construcción de un aparato económico nacional perdurable.

En el año 2003, las recomendaciones del FMI se basaron en que la importación de arroz fuera más barata que el grano local, y el apoyo en la exportación de café, incluso, bajo la saturación de precios y la producción por todo el 
mundo de este producto, con alrededor de 40.000 familias en Timor Oriental dependiendo del café como su principal fuente de ingresos. ¿No sería lo coherente en un país de pequeños agricultores el apoyar a los productores en la elaboración de grano para al menos garantizar la subsistencia de las comunidades y poder sacar el beneficio de los excedentes? (Gamero, 2005, p. 13).

Estos factores han impedido que las autoridades nacionales hayan tenido la suficiente autonomía para el diseño de su política económica. Se ha obstaculizado la priorización del interés nacional y la construcción de instituciones económicas que permitan la autosuficiencia de TimorLeste, debido a que se han creado nuevos lazos de dependencia económica con los estados fuertes, potencias regionales o mundiales.

Otro de los aspectos económicos en materia de política exterior, y que se debe resaltar, tiene que ver con la delimitación definitiva de la frontera marítima, tema en el que Australia se encuentra muy interesado por la presencia comprobada de recursos energéticos. Si bien es incierta la cantidad de recursos presente en esta área, algunas estimaciones indican que el Mar de Timor tiene reservas de alrededor de medio billón de barriles de petróleo y cerca de 10 trillones de pies cúbicos de gas (Lundahl, Sjoholm, marzo de 2008, p.79), cifras apreciables y cuya explotación podría garantizar un aceptable futuro económico para los timorenses.

Sin embargo, las complicaciones para la delimitación de la frontera marítima han impedido que Timor-Leste pueda acceder a la explotación de los recursos del Mar de Timor. Con el nacimiento estatal de Timor los reclamos sobre la frontera con Australia tomaron de nuevo despliegue. Australia mantiene una postura estatal acerca de que la delimitación de la frontera debe basarse en la plataforma continental, mientras que Timor-Leste plantea la demarcación de un límite marítimo meridional entre los dos estados.

Desde el año 1991 Indonesia comenzó a realizar las concesiones a las compañías internacionales para la explotación de los recursos del Mar de Timor. Portugal denunció estos acuerdos ante la Corte Internacional de Justicia (CIJ) por ilegalidad, debido a la ocupación del territorio timorense. Sin embargo, la ClJ no pudo invalidar los tratados, pues Indonesia no reconocía su jurisdicción (Gamero, 2005, p.13).

En 1999, bajo la administración de Timor por parte de UNTAET, se creó la Joint Petroleum Development Area (JPDA) como una zona de cooperación y explotación conjunta de los recursos. En el año 2003 Australia concedió para Timor-Leste el 90\% de los ingresos de la operación en la zona, aclarando que la totalidad de la JPDA se encuentra al norte de la línea media que aduce como límite con Australia. El asunto se encuentra en negociación, por cuanto Australia pretende el $80 \%$ de la zona, y el $20 \%$ restante para explotación conjunta, mientras que Timor pretende la totalidad de la zona. Australia ha condicionado el acuerdo a que el procesamiento del gas explotado se realice en su territorio (Rocamora, 2005, p. 184). 
Timor-Leste acusa a Australia de continuar la explotación solitaria y ha tomado la totalidad de los ingresos de zonas limítrofes con la JPDA sobre las cuales todavía no se ha establecido un acuerdo, y de las que Timor no ha obtenido ganancias. Actualmente la totalidad de la explotación energética de Timor-Leste se concentra en la JPDA y las áreas que se suponen más ricas en recursos siguen en litigio.

Después de la independencia de Timor, Australia ha desempeñado un papel de primer orden al participar de manera directa en su proceso de estabilización y reconstrucción, pero no creó las condiciones para la delimitación definitiva de la frontera marítima timorense conforme con el Derecho del Mar.

\section{CONCLUSIONES}

1. El análisis del desarrollo histórico de Timor Oriental deja en evidencia cómo las problemáticas que enfrenta en su actualidad son el resultado de las dinámicas de un proceso de colonización de características especiales, que se radicalizó con la anexión de Indonesia, lo cual postergó por más de dos décadas su conformación estatal independiente. Si bien los procesos de colonización y anexión tuvieron características diferentes, coincidieron en la carencia de condiciones para incentivar el desarrollo socio político en Timor, pues su principal interés consistió en la ocupación, dominación y expoliación del territorio.

2. Portugal, durante la colonización, se resistió a otorgarle independencia a Timor Oriental, a pesar de que su interés se centró en una focalizada explotación de los recursos de la isla y la perpetuación de sus dominios imperiales. De igual forma, la metrópoli colonizadora desestimuló la construcción de nación al incentivar conflictos entre los diversos grupos sociales, a fin de impedir el desarrollo de autonomía y de conciencia de derechos y valores democráticos.

3. El proceso de descolonización del territorio timorense fue truncado por la posterior anexión de Indonesia, operación que contó con la aprobación de Estados Unidos en el contexto de Guerra Fría. Indonesia justificó la ocupación del territorio bajo el esquema de una Gran Indonesia, el cual ha sido un elemento discursivo esencial para preservar su integridad estatal dentro de una configuración geopolítica compleja. El dominio indonesio se basó en el ejercicio de la fuerza y no se emprendió un proceso de asimilación cultural y social que permitiese integrar a la población timorense al Estado de Indonesia.

4. El prolongado proceso de descolonización que desembocó con la creación de Timor-Leste generó la instauración de una institucionalidad estatal, pero la problemática se transfiguró en la construcción de la nación timorense. Los siglos de dominio extranjero y las características del mismo impidieron la creación de identidad nacional y se dio un amplio vacío 
dentro del discurso historiográfico. En tal sentido, documentos como el Informe Chega se constituyen en importantes iniciativas que permiten suministrar una narrativa de la historia nacional, otorgándole el acceso de la información histórica a la población, incluyendo los acontecimientos más complejos. Sin duda estos esfuerzos permiten la reconciliación y el establecimiento de los pilares para el fortalecimiento de la identidad timorense. Aunque estos avances son significativos, las dinámicas actuales de Timor-Leste han puesto a prueba a la nación timorense y a su fortaleza como proyecto histórico de Estado Nación.

5. El proceso de formación de Estado en Timor-Leste se ha realizado dentro del modelo occidental, esto es, a través de la realización de un referéndum para la autodeterminación y, posteriormente, la celebración de elecciones para Parlamento, Jefe de Gobierno y Jefe de Estado. De igual manera se ha establecido una Constitución democrática, la cual refleja las estructuras e instituciones heredadas de la colonización portuguesa.

6. El concepto de Estado fallido es complejo, flexible y susceptible de críticas. Sin embargo, su aceptación por parte de la literatura se desprende de su utilidad analítica y comparativa. Se considera que el Estado fallido es aquel que es incapaz de asumir sus funciones básicas y brindar los bienes públicos esenciales, generando inconvenientes graves en aspectos sociales, económicos y político-militares, lo cual afecta los ámbitos institucionales referentes a la legitimidad interna y externa.

7. Timor-Leste es catalogado como un Estado fallido por diversos escalafones, como el de Fund For Peace, el cual lo ubica, según su sexta versión, en el puesto 18. Existen temas críticos que inciden en esa catalogación como son la injerencia extranjera en su política exterior, la crisis humanitaria referente a refugiados, la deslegitimación del Estado y las carencias en securitización. Sin embargo, no se debe considerar a Timor-Leste como un Estado paria dentro de la comunidad internacional, que pudiese estar condenado a su colapsamiento. Algunos elementos como su reciente creación estatal, su progresiva interacción en organizaciones internacionales y el lento pero racional proceso de construcción social de las instituciones son atenuantes que no permiten equiparar su situación con la de otros países señalados como estados fallidos: Corea del Norte, Haití, Afganistán o Somalia.

8. Uno de los problemas cruciales en la consolidación de la independencia de Timor-Leste es la urgencia en la construcción de nación. En este sentido, entre los retos más destacados que se deben afrontar se encuentra la necesidad de retomar las instituciones y tradiciones normativas ancestrales, disminuir las asimetrías sociales de las regiones frente a la capital, reconstruir una narrativa histórica propia, la alfabetización y la consolidación del tétum como idioma nacional. Así mismo, el futuro de la sostenibilidad macroeconómica del país depende de la autogestión racional de los recursos naturales, en especial de los hidrocarburos, aspecto en el que mantiene una controversia limítrofe con Australia, heredada a partir de los tratados firmados por este país con Indonesia durante la época de la anexión. 


\section{BIBLIOGRAFÍA}

- ACNUR. (2000). La situación de los refugiados en el mundo 2000. Cincuenta años de acción humanitaria. España: Icaria Editorial.

- Albarran, M. (2001) Panorama Lingüístico de Timor. Identidade Regional, Nacional e Pessoal. Revista Camões no14.

- Amnistía Internacional, (2009) Informe 2009 Amnistía Internacional. El estado de los derechos humanos en el mundo.

- Asimov, I. (1992). Cronología del Mundo. La historia del Mundo desde el Big Bang a los tiempos modernos. Barcelona: Ariel.

- Ayson, R. (Jun. de 2007). The «arc of instability» and Australia's strategic policy. Australian Journal of International Affairs, 61, 2, 215-231.

- Boegue, V; Brown, A; Clements, K y Nolan, A (2008). ¿Qué es lo «fallido»? ¿Los Estados del Sur, o la investigación y las políticas de Occidente? Un estudio sobre órdenes políticos híbridos y los Estados emergentes. Berghof Research Center for Constructive Conflict Managemente.

- Carcedo, D. (Jun. de 2007). Franco y Portugal. Treinta años de relaciones entre dos dictaduras. Historia y Vida, 471, 70-79.

- Comissão de Acolhimento, Verdade e Reconciliação, CAVR. (2005). iChega! http://www.cavr-timorleste.org/ (10 de jul. de 2010).

- Costa, L. (2001) O Tétum, factor de identidade nacional. Revista Camões nô14.

- Chesterman, S (2005). Making States Work: State Failure and the Crisis of Governance. United Nations University Press. 2005.

- De La Torre, H. y Sánchez, J. (1992). Portugal en el Siglo XX. La historia en sus textos. Madrid: Istmo. http:/ /books.google.com.co (10 de jul. de 2010).

- División de Noticias y Medios de Información del Departamento de Información Pública - Departamento de Operaciones de Paz. (n.d.). Timor Leste - UNMIT - Antecedentes. Obtenida el 6 de abril de 2010. http://www.un.org/spanish/Depts/dpko/unmit/background.html

- Donohue, M. \& Grimes, C. E. (Junio de 2008) Yet more on the position of the languages of Eastern Indonesia and East Timor. Oceanic Linguistics, 47, 1, 114-158.

- Durand, F. (2006) East Timor. A country at the crossroads of Asia and the Pacific: A Geo-Historical Atlas 1a. ed., Bangkok, Silkworm Books.

- Durand, F. (2006). East Timor. A country at the crossroads of Asia and the Pacific: A Geo-Historical Atlas. Silkworm Books: Bangkok. 
- El Mundo. (Abr. 2008). Agencias internacionales retiran a su personal de Timor Oriental por riesgo de secuestro. Obtenida el 12 de abril de 2010. http://www.elmundo.es/elmundo/2008/04/07/solidaridad/ 1207566518.html

- Engel, R. (2006) The Crisis in Timor-Leste: Restoring National Unity through State Institutions, Culture, and Civil Society. Madrid, Fundación para las Relaciones Internacionales y el Diálogo Exterior (FRIDE).

- Fund for Peace (2010). Index of failed states. www.fundforpeace.org (24 de jul. de 2010).

- Gamero, J. (2005). Timor Oriental: ¿una experiencia única y exitosa de reconstrucción? VII Congreso Español de Ciencia Política y de la Administración: Democracia y Buen Gobierno.

- Hicks, D. (Feb. de 2007). Community and nation-state in East Timor. A view from the periphery. Anthropology Today, 1, 13-16.

- Hobsbawm, E. (2008). Historia del Siglo XX. Barcelona: Crítica.

- IRASEC, East-Timor. (2009) How to built a new nation in Southeast Asia in the $21^{\text {st }}$ century? Occasional Paper $n^{\circ} 9$.

- Kingsbury, D. y Leach, M. (2007). East Timor: Beyond independence. Clayton: Monash University Press.

- Krieger, H. y Rauschning, D. (1994). East Timor and the international community: basic documents. Cambridge: Cambridge University Press. http://books.google.com.co (10 de jul. de 2010).

- Lundahl, M, Sjoholm, F. (Mar. 2008). The oil resources of Timor-Leste: curse or blessing? The pacific Review. Vol 21 No. 1.

- Lundahl, M. y Sjöholm, F. (Marzo 2008). The oil resources of Timor-Leste: curse or blessing? The Pacific Review, 1, 67-86.

- Made, S. (27 de mar. de 2010). Entrevista personal al Ministro Consejero en la Embajada de Indonesia en Colombia, Bogotá.

- Manjikian, M. (Jul-sep 2008). Diagnosis, Intervention, and Cure: The Illness Narrative in the Discourse of the failed state. Alternatives: Global, Local, Political, 33, 3, 335-357,

- Mcwilliam, A; Bexley, A. (Mar. 2008). Performing politics: the 2007 parliamnetary elections in TimorLeste. The Asia Pacific journal of anthropology Vol 9, No. 1.

- Monroy, M. G. (2002). Derecho internacional público. Bogotá: Temis.

- Oxford International. (Sep. 2009). Failed states test international system. Oxford Analytical Daily Brief Service 2009.

- Rocamora, J. (2005) Timor Oriental tras la ocupación indonesia. Revista CIDOB d'Afers Internacionals, num. 69, p. 173-194. 
- Roosa, J. (Abril 2007). Finalising the nation: The Indonesian military as the guarantor of national unity, Asia Pacific Viewpoint, 48, 1, 99-111.

- Roosa, J. (Inv. 2007-2008). How Does a Truth Commission Find Out What the Truth Is? The Case of East Timor's CAVR, Pacific Affairs, 80, 4, 569-580.

- Rotberg, R. (2003). State Failure and State Weakness in a Time of Terror., Washington, DC: Brookings Institution Pres.

- Ruak, T. (2001) A importância da língua portuguesa na resistência contra a ocupação indonésia. Revista Camões № 14.

- Schofield, C. (2007). Minding the Gap: The Australia-East Timor Treaty on Certain Maritime Arrangements in the Timor Sea (CMATS). The International Journal of Marine and Coastal Law, 22, 2, 189-234.

- Simonsen, S. (Oct. 2008) Identidad desde la violencia: la nueva división este-oeste en Timor Oriental. Revista Académica de Relaciones Internacionales, GERI-UAM.

- Sur, S. (2005). Sur les États défaillants. Commentaire 112, 891-899.

- Taylor, J. G. (2001). The emergence of nationalism movement in East Timor. En Kratoska, P. (Ed.), South East. Colonial history. Londres: Routhledge.

- Tejada, C. (24 de may. de 2010). Entrevista realizada en la Universidad Libre, Sede Candelaria, Bogotá.

- Webster, D. (2007). History, nation and narrative in East Timor's Truth Commission Report, 80 Pacific Affairs, 581-591.

- Webster, D. (Abr. de 2007). From Sabang to Merauke: Nationalist secession movements in Indonesia. Asia Pacific Viewpoint, 48, 1, 85-98.

- Zervaki, A. (Octubre de 2008). United Nations at crossroads: International administration of territories and domestic political cultures. The Kosovo and East Timor experience. UNISCI Discussion Papers, 18, 9-19. 